\title{
Effect of High-Pressure Homogenization, Nonfat Milk Solids, and Milkfat on the Technological Performance of a Functional Strain for the Production of Probiotic Fermented Milks
}

\author{
F. Patrignani, ${ }^{* 1}$ L. Iucci, ${ }^{*}$ R. Lanciotti, ${ }^{*}$ M. Vallicelli, ${ }^{*}$ J. Maina Mathara, $†$ W. H. Holzapfel,ł \\ and M. E. Guerzoni* \\ *University of Bologna, Dipartimento di Scienze degli Alimenti, Piazza Goidanich, 60, 47023 Cesena, Italy \\ †Jomo Kenyatta University of Agriculture and Technology, Department of Food Science and Technology, PO Box 62000, Nairobi, Kenya \\ ‡Federal Research Centre for Nutrition and Food, Institute of Hygiene and Toxicology, Haid-und-Neu-Str. 9, D-76131 Karlsruhe, Germany
}

\begin{abstract}
The aim of this research was the evaluation of the effects of milkfat content, nonfat milk solids content, and high-pressure homogenization on 1) fermentation rates of the probiotic strain Lactobacillus paracasei BFE 5264 inoculated in milk; 2) viability loss of this strain during refrigerated storage; and 3) texture parameters, volatile compounds, and sensorial properties of the coagula obtained. The data achieved suggested a very strong effect of the independent variables on the measured attributes of fermented milks. In fact, the coagulation times were significantly affected by pressure and added milkfat, and the rheological parameters of the fermented milk increased with the pressure applied to the milk for added nonfat milk solids concentrations lower than 3\%. Moreover, the polynomial models and the relative response surfaces obtained permitted us to identify the levels of the 3 independent variables that minimized the viability loss of the probiotic strain used during refrigerated storage.
\end{abstract}

Key words: probiotic fermented milk, response surface methodology, high-pressure homogenization, Lactobacillus paracasei

\section{INTRODUCTION}

Fermented dairy products are perceived by consumers as healthy products because they represent good sources of vitamins and minerals and generally contain low amounts of lipids. The starter cultures of traditional yogurt, Streptococcus thermophilus and Lactobacillus delbrueckii ssp. bulgaricus, improve the nutritional content and digestibility of the fermented

Received May 18, 2007

Accepted June 7, 2007.

${ }^{1}$ Corresponding author: francesca.patrignani@unibo.it product, although they are not usually part of the indigenous microbiota of the mammalian intestine (Mitsuoka, 1992) and have limited survival after oral ingestion (Bertazzoni Minelli et al., 2004). The use of probiotic (health-promoting) microorganisms in different fermented milks or yogurt-like products has reinforced the acclaimed healthful properties and increased the consumption of these products. Probiotics are reported to beneficially affect the host because they improve the balance of its intestinal bacterial ecosystem (Ouwehand et al., 1999). Moreover, several immune responses have been reported to be influenced by probiotics. To exert these healthy benefits in the host, the probiotic microorganisms need to be viable, active, and sufficiently abundant (i.e., in concentrations of at least $10^{7} \mathrm{cfu} / \mathrm{g}$ in the product) throughout the specified shelf life (Vinderola et al., 2000).

In addition to the health-promoting effects, the overall properties of fermented milks, such as acidity level, free fatty acid content, the production of aroma compounds (diacetyl, acetaldehyde, acetoin), the sensory profile, and nutritional value are important product traits affecting acceptability by consumers. Consequently, the ability to impart good sensory properties to the final product is included in the selection criteria of the probiotic cultures (Saarela et al., 2000; MattilaSandholm et al., 2002). However, fermented milks obtained from the direct and sole use of probiotic strains are often characterized by the lack of desirable sensory features (Marshall and Cole, 1983). To improve their texture and body, several strategies have been proposed. In particular, the use of strains able to produce exopolysaccharides has been suggested as alternatives to additives such as xanthan gum, gelatin, pectin, and carrageenan (Lucey, 2004), which can adversely affect the product taste, flavor, aroma, and mouthfeel (De Ancos et al., 2000). Also, coinocula of probiotic strains with Lb. delbrueckii ssp. bulgaricus and Strep. thermophilus have been reported to improve the sensorial properties of fermented milks (Gomes and Malcata, 
1999). Moreover, Strep. thermophilus is applied to sustain the mild acid fermentation typical of yogurt containing probiotic lactobacilli (Holzapfel et al., 1998). The improvement of technological strain features and sensory properties of fermented milks has been obtained by modulating some physicochemical and technological variables commonly used at the industrial level. In particular, some literature reports indicate that response surface methodology is a useful tool to evaluate the simultaneous effects of some important technological, compositional, and microbiological variables on the acidification rate of starter bacteria (including probiotic strains), on their viability losses during product refrigerated storage, and on product sensory traits (Gardini et al., 1999; Kristo et al., 2003; Patrignani et al., 2006). Among technological variables, high-pressure homogenization (HPH) of milk is reported to be useful to increase or modulate the viscosity of fermented milk without detrimental effects on shelf life and safety (Lanciotti et al., 2004b). According to the literature data, this treatment has potential for several applications such as microbial (Lanciotti et al., 1996; Guerzoni et al., 2002; Vachon et al., 2002) and bacteriophage inactivation (Thiebaud et al., 2003), modification of the microstructure and rheology of food emulsions (Guerzoni et al., 1997; Floury et al., 2000), improvement of the body and texture of yogurts and cheeses (Lanciotti et al., 2004b), increasing cheese yield, and reduction of ripening time due to the enhanced susceptibility of proteins and triglycerides to proteolysis and lipolysis, respectively (Kheadr et al., 2002; Lanciotti et al., 2004a; Lopez-Fandiño et al., 1998), and activation or inactivation of enzymes (Hayes and Kelly, 2003; Vannini et al., 2004; Iucci et al., 2006). The most promising applications in dairy industry include the development of new products differentiated by sensory and structural characteristics and with different functional properties compared with traditional products (Kheadr et al., 2002).

In this perspective, the overall aim of the work was to evaluate the combined effects of HPH levels (P), milkfat content $(\mathbf{F})$, and nonfat milk solids content $(\mathbf{S})$ on the sensorial features of fermented milks obtained using a strain endowed with probiotic activity (Mathara et al., 2004) as starter culture. In particular, the effects of F, S, and P, modulated according to a central composite design (CCD), were evaluated with respect to fermentation rates and viability losses during refrigerated storage of the Lactobacillus paracasei $\mathrm{BFE}$ 5264 , as well as on the aroma, sensorial, and texture profiles of the coagula obtained. Moreover, the effects of the addition phase of $\mathrm{F}$ (before or after the pressure treatment) on the technological performances of the strain $L b$. paracasei BFE 5264 were assessed.
Table 1. Pressure levels, nonfat milk solids, and milkfat percentages used in the experimental design; the basal medium was raw whole milk

\begin{tabular}{lccc}
\hline Run & $\begin{array}{c}\text { Pressure } \\
(\mathrm{MPa})\end{array}$ & $\begin{array}{c}\text { Milk solids }^{1} \\
(\%)\end{array}$ & $\begin{array}{c}\text { Milkfat }^{2} \\
(\%)\end{array}$ \\
\hline 1 & 40 & 1.5 & 0.75 \\
2 & 80 & 1.5 & 0.75 \\
3 & 40 & 4.5 & 0.75 \\
4 & 80 & 4.5 & 0.75 \\
5 & 40 & 1.5 & 2.25 \\
6 & 80 & 1.5 & 2.25 \\
7 & 40 & 4.5 & 2.25 \\
8 & 80 & 4.5 & 2.25 \\
9 & 60 & 3.0 & 1.50 \\
10 & 60 & 3.0 & 1.50 \\
11 & 20 & 3.0 & 1.50 \\
12 & 100 & 3.0 & 1.50 \\
13 & 60 & 0.0 & 1.50 \\
14 & 60 & 6.0 & 1.50 \\
15 & 60 & 3.0 & 0.00 \\
16 & 60 & 3.0 & 3.00 \\
17 & 60 & 3.0 & 1.50 \\
\hline
\end{tabular}

${ }^{1}$ Sterile skim powder (Oxoid, Basingstoke, UK) was used as nonfat milk solids.

${ }^{2}$ UHT cream (Parmalat, Parma, Italy) was used as milkfat.

\section{MATERIALS AND METHODS}

\section{Strain}

Lactobacillus paracasei BFE 5264, isolated from fermented Masaai milk and previously tested for its probiotic (Mathara et al., 2004) and technological features (Patrignani et al., 2006), was obtained from the culture collection of the Institute of Hygiene and Toxicology, Food Research Centre for Nutrition and Food (Karlsruhe, Germany).

\section{Preparation of Inoculating Culture}

Lactobacillus paracasei BFE 5264 was cultured in de Man, Rogosa, and Sharpe (MRS) broth (Oxoid, Basingstoke, UK), at $37^{\circ} \mathrm{C}$. Twenty milliliters of overnight culture was transferred to $1,000 \mathrm{~mL}$ of reconstituted skim milk (Oxoid) and incubated at $37^{\circ} \mathrm{C}$ for 12 $\mathrm{h}$. The inoculating culture count was determined on MRS agar under anaerobic conditions by using Anaerocult (Merck, Darmstadt, Germany), and plates were incubated at $37^{\circ} \mathrm{C}$ for $48 \mathrm{~h}$.

\section{Production of Fermented Milk}

Fermented milks were produced by using whole, raw milk treated with different HPH levels $(\mathrm{P})$ and with different levels of milkfat (F) and nonfat milk solids (S), according to the two " 3 factor $\times 5$ level" CCD (Box et al., 1978) reported in Table 1 . The 2 CCD differed in the time of the addition of $\mathrm{F}$ (i.e., before or after the 
Table 2. Best-fit equations relative to the effects of pressure level, time of milkfat supplementation, and nonfat milk solids concentrations on the fermentation time and viability of Lactobacillus paracasei BFE 5264 inoculated in basal medium with UHT cream added before and after homogenization

\begin{tabular}{llcrr}
\hline Equation number $^{1}$ & \multicolumn{1}{c}{ Equation $^{2}$} & $\mathrm{R}^{3}$ & $F$-value & $\mathrm{SE}$ \\
\hline [1] Fermentation time (after) $=$ & $0.15[\mathrm{P}]+5.821[\mathrm{~F}]-0.10[\mathrm{P}][\mathrm{F}]$ & 0.96 & 77.37 & 3.40 \\
[2] Fermentation time (before) $=$ & $0.30[\mathrm{P}]+10.680[\mathrm{~F}]-0.20[\mathrm{P}][\mathrm{F}]$ & 0.96 & 80.31 & 4.80 \\
[3] Viability at 0 d (after) $=$ & $0.15[\mathrm{P}]+5.821[\mathrm{~F}]-0.10[\mathrm{P}][\mathrm{F}]$ & 0.96 & 80.45 & 2.51 \\
[4] Viability at 0 d (before) $=$ & $0.13[\mathrm{P}]+2.540[\mathrm{~S}]-0.04[\mathrm{P}][\mathrm{S}]$ & 0.97 & 91.37 & 2.16 \\
[5] Viability at 30 d (after) $=$ & $0.14[\mathrm{P}]+2.801[\mathrm{~S}]-0.04[\mathrm{P}][\mathrm{S}]$ & 0.96 & 80.84 & 2.43 \\
[6] Viability at 30 d (before) $=$ & $0.10[\mathrm{P}]+1.021[\mathrm{~S}]-0.08[\mathrm{P}][\mathrm{S}]$ & 0.97 & 79.05 & 2.45 \\
\hline
\end{tabular}

\footnotetext{
${ }^{1}$ After and before refer to timing of supplementation with fat relative to the homogenization process.

${ }^{2}[\mathrm{P}]=$ pressure level $(\mathrm{MPa}) ;[\mathrm{F}]=$ milkfat $(\%) ;[\mathrm{S}]=$ nonfat milk solids $(\%)$. Only terms with $P<0.05$ were included.

${ }^{3}$ Regression coefficient.
}

HPH treatment). The different levels of $\mathrm{F}$ and $\mathrm{S}$ were obtained by adding different concentrations of UHT cream (Parmalat, Parma, Italy) and skim milk powder (Sacco srl, Cadorago, Italy), respectively. For each run considered, $1,000 \mathrm{~mL}$ of fresh whole milk was added to skim milk powder, according to the CCD levels, and heated at $105^{\circ} \mathrm{C}$ for $7 \mathrm{~min}$. Then, the mixtures were cooled and subjected to HPH treatment, according to the pressure level established by the experimental designs. For each run considered, the treated milk was divided among 100-mL sterile containers. The established levels of UHT cream were added before or after the homogenization treatment. The inoculum was added at $2 \%$, at a level of $6 \log \mathrm{cfu} / \mathrm{mL}$, after homogenization. After inoculation, the samples were incubated at $37^{\circ} \mathrm{C}$. During fermentation, the $\mathrm{pH}$ was monitored until the reaching $\mathrm{pH} 4.6$; then, the samples were stored at $4^{\circ} \mathrm{C}$.

\section{HPH Treatment}

A continuous high-pressure homogenizer (Panda, Niro Soavi, Parma, Italy) was used for all homogenizing treatments. The machine was supplied with a standard homogenizing type valve; the valve assembly included a ceramic ball-type impact head, a stainless steel impact ring, and a tungsten carbide passage head. The inlet temperature of samples was 2 to $4^{\circ} \mathrm{C}$ and the increase rate of temperature was $3^{\circ} \mathrm{C} / 10 \mathrm{MPa}$.

\section{pH Measurements}

The acidification rates were measured by using a pH meter (Hanna Instruments 8519, Incofar, Modena, Italy). The data collected are the mean of 3 independent repetitions.

\section{Viability of Lactobacillus paracasei BFE 5264}

The cell loads of $L b$. paracasei in fermented milks were evaluated after $12 \mathrm{~h}$ and again after $30 \mathrm{~d}$ of refrig- erated storage. Ten grams of sample was diluted into $90 \mathrm{~mL}$ of sterile saline water $(9 \mathrm{~g} / \mathrm{L})$ and homogenized in a stomacher (Lab Blender 80, PbI International, Milan, Italy) for $2 \mathrm{~min}$. Decimal dilutions of the homogenate were made in sterile saline water, and $0.1 \mathrm{~mL}$ of the appropriate dilution was spread onto the surface of MRS agar (Oxoid); the plates were incubated at $37^{\circ} \mathrm{C}$ for $48 \mathrm{~h}$ under anaerobic conditions. The results are the mean of 3 repetitions.

\section{Fermented Milk Textural Measurement}

After $12 \mathrm{~h}$ storage at $4^{\circ} \mathrm{C}$, all the fermented milks obtained were analyzed for their textural features. Firmness, consistency, cohesiveness, and viscosity indexes were evaluated using a back extrusion cell (A/ $\mathrm{AB}$ ) on a Texture Analyzer TA DHI (Stable Micro System, Godalming, UK) according to the manufacturer's instructions. A solid rod ( $35 \mathrm{~mm}$ diameter) was inserted into a cylindrical container (48 $\mathrm{mm}$ diameter) holding $100 \mathrm{~mL}$ of sample using a 5 -kg load cell. Three independent measures were performed for each yogurt type obtained.

\section{Aroma Profile}

Fermented milk aroma compounds were monitored $12 \mathrm{~h}$ after coagulation and after $30 \mathrm{~d}$ of refrigerated storage by using GC-MS coupled with solid-phase microextraction. For each coagulum, $5 \mathrm{~g}$ of sample was sealed in a sterilized vial. Samples were heated at $40^{\circ} \mathrm{C}$ for $20 \mathrm{~min}$ and volatiles adsorbed for $40 \mathrm{~min}$ on a fused-silica fiber covered by carboxen polydimethyl siloxane, $75 \mu \mathrm{m}$ (Supelco, Sigma-Aldrich Chemie GmbH, Munich, Germany). Adsorbed molecules were desorbed in the gas chromatograph for $5 \mathrm{~min}$. For peak detection, a gas chromatograph (Agilent 6890GC, Agilent Technologies, Milan, Italy) equipped with an MS detector (5970 MSD, Agilent) and a $50 \mathrm{~m} \times 0.32$ i.d. fused-silica capillary column coated with a $1.2-\mu \mathrm{m}$ 
polyethylene glycol film (Chrompack CP-Wax $52 \mathrm{CB}$ ) as stationary phase were used. The conditions were as follows: injection temperature, $220^{\circ} \mathrm{C}$; detector temperature, $220^{\circ} \mathrm{C}$; carrier gas $(\mathrm{He})$ flow rate, $1.5 \mathrm{~mL} /$ min; splitting ratio, 1:20 ( $\mathrm{vol} / \mathrm{vol})$. The oven temperature was programmed as follows: from 50 to $65^{\circ} \mathrm{C}$, increasing at $1^{\circ} \mathrm{C} / \mathrm{min}$; from 65 to $220^{\circ} \mathrm{C}$, increasing at $3.5^{\circ} \mathrm{C} / \mathrm{min}$, and then holding for $10 \mathrm{~min}$. Three replicates were performed for each yogurt type obtained.

\section{Panel Test}

To evaluate and compare the sensory attributes of the different fermented milks obtained, an unstructured panel test was performed after $30 \mathrm{~d}$. Twentyfive trained evaluators each tasted $25 \mathrm{~g}$ of each sample served at $15^{\circ} \mathrm{C}$ under controlled conditions of environment and light according to ISO Standard 8589 (ISO, 1988). The assessors were asked to evaluate coagula color, flavor, taste, and firmness and attribute a score ranging from 0 (very poor) to 10 (excellent).

\section{Statistical Analysis}

The acidification, microbiological, textural, and volatile compound data recorded were modeled using Statistica for Windows (Statsoft, Tulsa, OK) to fit the second-order model to dependent variables (i.e., cell loads, acidification rates, rheological indexes, and volatile compound production). The variables with significance lower than $95 \%(P>0.05)$ were not included in the finals models. Three-dimensional surface plots were drawn to illustrate the major and interactive effects of the independent variables on the dependent ones. These graphs were drawn imposing a constant value (i.e., the central points of the interval taken into consideration) to one independent variable.

Averaged data from the assessor panel were analyzed by 1-way ANOVA using Statistica for Windows (v. 6.1, Statsoft). The ability of each descriptor to discriminate between samples was investigated according to the posthoc comparisons of the ANOVA.

\section{RESULTS}

\section{Coagulation Time and Viability}

To evaluate the importance of fat addition time, the technological performances of the strain Lactobacillus paracasei BFE 5264 were observed when UHT cream was added before the HPH process and compared with those recorded when fat was supplemented after homogenization. The data collected in the different runs of the 2 CCD were modeled according to polynomial quadratic equations to identify the independent vari-

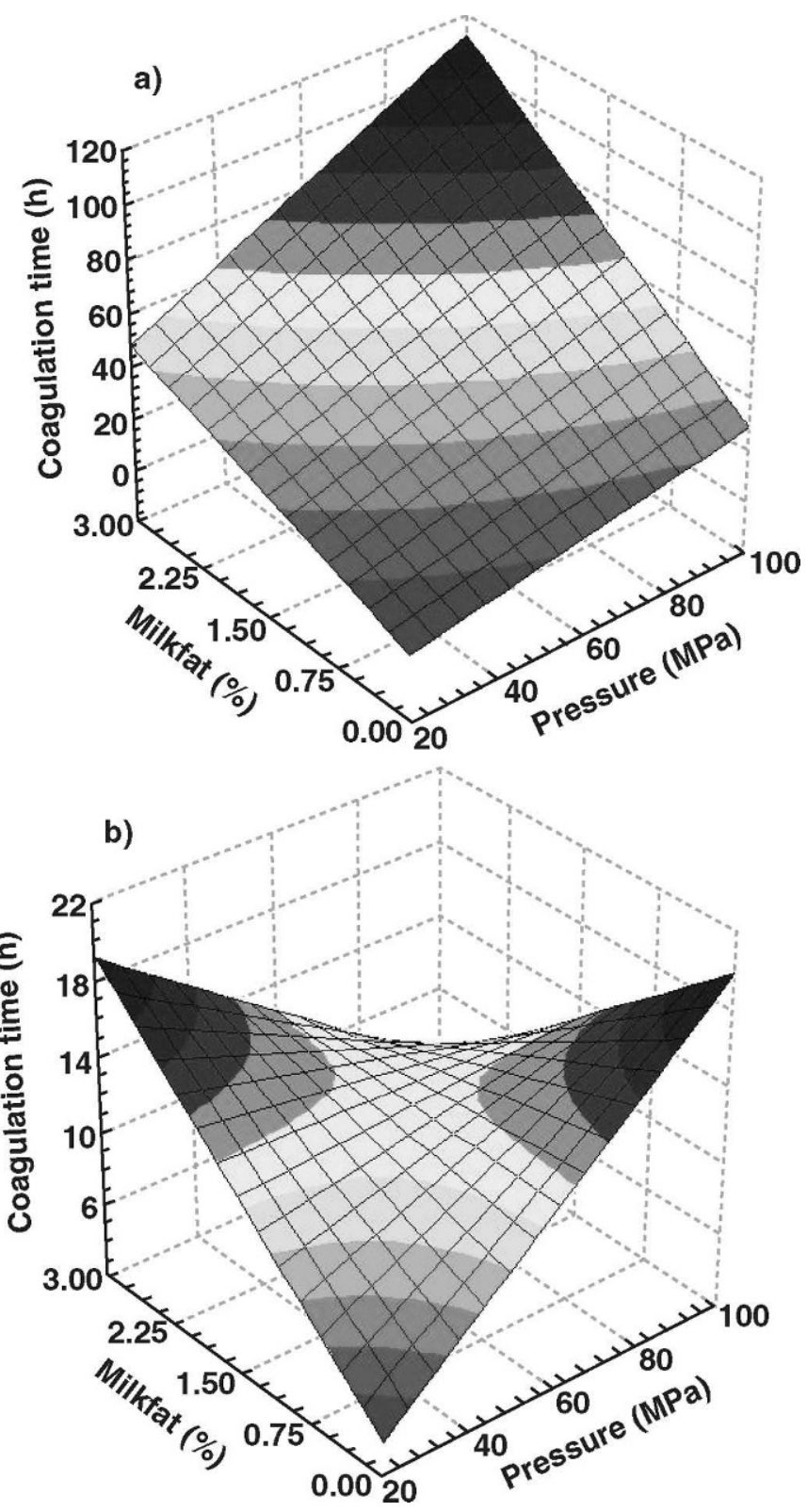

Figure 1. Three-dimensional contour plots showing the effects of the interactions $[\mathrm{P}] \times[\mathrm{F}]$ on Lactobacillus paracasei $\mathrm{BFE} 5264$ coagulation time in basal medium containing milkfat added (a) before and (b) after homogenization treatment. $[\mathrm{P}]=$ homogenization pressure level $(\mathrm{MPa}) ;[\mathrm{F}]=\operatorname{milkfat}(\%)$.

ables that significantly affected the fermentation rate and the cell loads of the strain after $12 \mathrm{~h}$ from coagulation and during the 30 -d storage. The best-fit equations obtained and reported in Table 2 allowed us to evaluate the effects of linear, quadratic, and interactive terms of the independent variables $(\mathrm{P}, \mathrm{F}$, and $\mathrm{S})$ on the chosen dependent variables. To better understand the interactive effects of the independent variables, surface plots were drawn. The coagulation times of the strain 
Table 3. Best-fit equations relative to the effects of pressure level, milkfat, and nonfat milk solids concentrations on texture parameters (after $12 \mathrm{~h}$ of refrigerated storage) of the coagula obtained with unhomogenized UHT cream by Lactobacillus paracasei BFE 5264 fermentation.

\begin{tabular}{llcrr}
\hline Equation number & \multicolumn{1}{c}{ Equation $^{1}$} & $\mathrm{R}^{2}$ & $F$-value & \multicolumn{1}{c}{$\mathrm{SE}$} \\
\hline$[1]$ Consistency $=$ & $110.0[\mathrm{P}]+1,321.0[\mathrm{~F}]-35.53[\mathrm{P}][\mathrm{S}]+263.616[\mathrm{~S}]^{2}$ & 0.96 & 45.53 & $1,665.50$ \\
{$[2]$ Firmness $=$} & $6.00[\mathrm{P}]+66.320[\mathrm{~F}]-2.03[\mathrm{P}][\mathrm{S}]+13.550[\mathrm{~S}]^{2}$ & 0.96 & 31.24 & 102.10 \\
{$[3]$ Cohesiveness $=$} & $-107.0[\mathrm{P}]+2,182.320[\mathrm{~S}]-34.0[\mathrm{P}][\mathrm{S}]+2.0[\mathrm{P}]^{2}$ & 0.95 & 7.30 & $1,498.70$ \\
{$[4]$ Viscosity index $=$} & $6.04[\mathrm{P}]-1.80[\mathrm{P}][\mathrm{S}]+18.303[\mathrm{~S}]^{2}$ & 0.96 & 75.94 & 70.46 \\
\hline \multicolumn{1}{l}{$[\mathrm{P}]=$ pressure level $(\mathrm{MPa}) ;[\mathrm{F}]=$ milkfat $(\%) ;[\mathrm{S}]=$ nonfat milk solids $(\%)$. Only terms with $P<0.05$ were } \\
included. \\
$\quad{ }^{2} \mathrm{R}=$ regression coefficient.
\end{tabular}

were significantly affected only by $\mathrm{P}$ and $\mathrm{F}$ levels, independently on the fat addition moment (equations [1] and [2], Table 2). When the addition of the fat was performed before the HPH treatment, the increase of $\mathrm{P}$ and $\mathrm{F}$ extended the coagulation times (Figure 1a). In contrast, the coagulation times were reduced by increasing $\mathrm{P}$ and $\mathrm{F}$ levels, especially when $\mathrm{F}$ was greater than 2.25 and supplemented after the homogenizing treatment (Figure 1b). The moment of addition of $\mathrm{F}$ is very important because it can affect the $L b$. paracasei cell loads (equations [3] and [4], Table 2). When the milk treatment was performed before the addition of fat, the $L b$. paracasei BFE 5264 cell loads were influenced positively by $\mathrm{P}$ and $\mathrm{F}$ as individual terms and negatively by their interaction. In the samples in which fat was added before the homogenizing process, the cell loads were positively affected by $\mathrm{P}$ and $\mathrm{S}$ and negatively affected by their interaction. In addition, with respect to strain viability after coagulation and during storage (data not shown), the raw data underline the key role of fat addition time in the process. In fact, when UHT cream was added after the HPH treatment, the cell loads of the strain $L b$. paracasei ranged between 8.5 and $9.0 \mathrm{log} \mathrm{cfu} / \mathrm{g}$. Lower levels (between 7.5 and $8.5 \mathrm{log} \mathrm{cfu} / \mathrm{g}$ ) were recorded when UHT cream was added before HPH. Moreover, after $30 \mathrm{~d}$ of refrigerated storage, the samples supplemented with fat before homogenization maintained greater viability of the starter. Due to the better performance (high viability during storage and low coagulation times) of the strain $L b$. paracesei BFE 5264, the texture and aroma profiles as well as the panel test were performed on samples obtained according to the CCD with cream added after homogenization.

\section{Texture Analysis}

The data recorded were modeled according to the polynomial quadratic equations and the best-fit equations are reported in Table 3 . The $\mathrm{P}$ and $\mathrm{S}$ levels affected significantly all the considered indices, whereas the $\mathrm{F}$ level influenced only the coagulum consistency and firmness. Firmness was increased by a greater level of $\mathrm{P}$, when $\mathrm{S}$ was $<3 \%$ (Figure 2a). For greater levels of S, enhancement of pressure level determined a decrease of firmness. Firmness was also enhanced by higher levels of F (data not shown). Analogous behavior, in relation to the $\mathrm{P}$ level and the $\mathrm{S}$ and $\mathrm{F}$ amounts, was also observed for viscosity index (Figure $2 b$ ) and consistency parameter (data not shown).

\section{Aroma Profile}

Although with quantitative differences, acetaldehyde, diacetyl, 2-propanone, acetoin, ethyl acetate, ethanol, 2,3-butandiol, and isoamylic alcohol were detected in all samples after $12 \mathrm{~h}$ of storage at $4^{\circ} \mathrm{C}$. These compounds, except acetoin, were also recorded in all samples after $30 \mathrm{~d}$ of storage. The best-fit equations obtained by modeling the GC peak area of the compounds are reported in Tables 4 and 5 . All of the independent variables significantly affected, as individual, interactive, or quadratic terms, the contents of diacetyl, ethyl acetate, and isoamylic alcohol immediately after ripening at $4^{\circ} \mathrm{C}$. Figure $3 \mathrm{a}$ (obtained from equation [1], Table 4) shows the specific values of pressure (60 to $80 \mathrm{MPa}$ ) and UHT cream (1.5\%) levels that maximized diacetyl accumulation. A stimulating effect on diacetyl content was exhibited also by the amount of $\mathrm{S}$, particularly at $\mathrm{P}$ levels $>40 \mathrm{MPa}$ (data not shown). The accumulation of acetaldehyde and 2,3-butandiol depended significantly on $\mathrm{F}$ and $\mathrm{P}$ levels applied. As shown in Figure 3b, the $\mathrm{P}$ level exhibited an opposite effect on the acetaldehyde content depending on the UHT cream concentration. In fact, acetaldehyde peak areas increased with $\mathrm{P}$ for UHT cream addition $<1.5 \%$. For higher UHT levels, an increase in $\mathrm{P}$ caused a decrease of acetaldehyde. On the contrary, the increase in $\mathrm{P}$ markedly enhanced the 2,3-butandiol content, particularly when the F level was $<2.25 \%$ (data not shown). As shown by equations [2] and [5] (Table 4), the HPH treatment did not have a significant effect on the 2-propanone and ethanol peak areas. However, on the basis of Figure 3c, it was possible to identify 

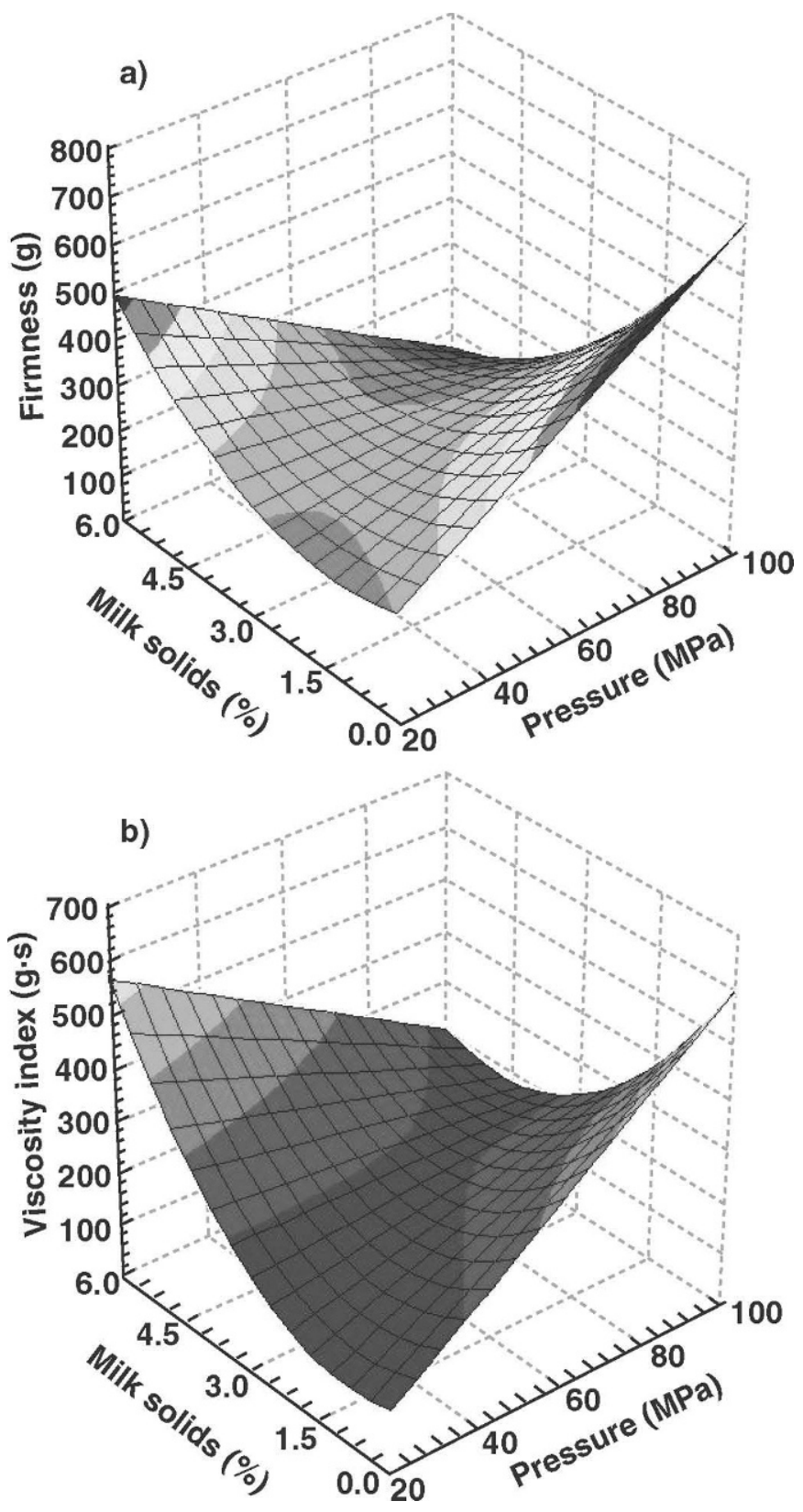

Figure 2. Three-dimensional contour plots showing the effect of the interaction $[\mathrm{P}] \times[\mathrm{S}]$ on the $(\mathrm{a})$ firmness $(\mathrm{g})$ and $(\mathrm{b})$ index of viscosity $(\mathrm{g} \cdot \mathrm{s})$ of the final products after $12 \mathrm{~h}$ of refrigerated storage. $[\mathrm{P}]=$ homogenization pressure level $(\mathrm{MPa}) ; \mathrm{S}]=$ nonfat milk solids $(\%)$.

the specific concentrations of skim milk $(3.0 \%)$ and UHT cream $(1.5 \%)$ able to maximize the 2-propanone peak area. After $30 \mathrm{~d}$ of storage, significant equations were obtained only for diacetyl, acetaldehyde, ethyl acetate, ethanol, and acetic acid. At the end of storage, the UHT cream concentration did not affect the diacetyl peak area any further. In fact, diacetyl was influenced positively by a pressure increase with skim milk concentration $<3 \%$, and by the skim milk enhancement for pressure levels $>80 \mathrm{MPa}$ (Figure 4). Analogous behavior, in relation to pressure and skim milk levels, showed the acetic acid accumulation (data not shown). The acetaldehyde peak area was significantly and positively affected by pressure, when expressed as $[\mathrm{P}]^{2}$, whereas ethanol accumulation depended only on the skim milk concentration. Ethyl acetate and acetic acid peak areas were improved by the pressure level increase when UHT cream was $<1.5 \%$, or by UHT cream supplementation for pressure $<80 \mathrm{MPa}$ (data not shown).

\section{Panel Test}

To assess the significant differences among the descriptors used, a 1-way ANOVA was performed. The results obtained are reported in Table 6. Moderate differences were found for the descriptor "color" in which the samples obtained from runs 3 and 4 differed significantly from fermented milks obtained from the run 1. By contrast, significant differences were recorded among groups of runs for firmness, taste, and flavor. The highest firmness scores were shown by runs $1,3,4,7,8$, and 15 , which significantly differed from runs 2,5 , and 6 , which were characterized by the lowest scores. Intermediate values were observed for the remaining. Significant diversities were recorded for the descriptor "taste." The greatest scores were obtained for run 1, whereas the lowest were obtained for the runs $2,9,10,15,16$, and 17 , which were significantly lower. The flavor scores indicated that the most liked fermented milks resulted from run $1(\mathrm{P}=40$ $\mathrm{MPa} ; \mathrm{S}=1.5 \% ; \mathrm{F}=0.75 \%)$ and run $8(\mathrm{P}=80 \mathrm{MPa}$; $\mathrm{S}=4.5 \% ; \mathrm{F}=2.25 \%$ ), which obtained the greatest evaluation scores.

\section{DISCUSSION}

The texture of fermented milks is an important criterion for quality assessment and it plays an important role in consumer acceptance (Herrero and Requena, 2006). It is well known that fermented milk texture depends mainly on the protein network formed by casein micelle strings or clusters that entrap serum and fat globules (Kaláb et al., 1983). Protein content, heat treatment, milk fat concentration, stabilizer agents, and bacterial exopolysaccharides are factors that directly affect the protein matrix of fermented milks (Lucey, 2004). The viscosity and firmness of milks are reported to depend primarily on TS and protein content and type (Oliveira et al., 2001). However, the present work demonstrated that, for an established composition of basal medium, the texture of fermented milks 
Table 4. Best-fit equations relative to the effects of pressure level, milkfat, and nonfat milk solids concentrations on aroma compound accumulation, after $12 \mathrm{~h}$ of refrigerated storage, in coagula obtained with unhomogenized UHT cream by Lactobacillus paracasei BFE 5264 fermentation

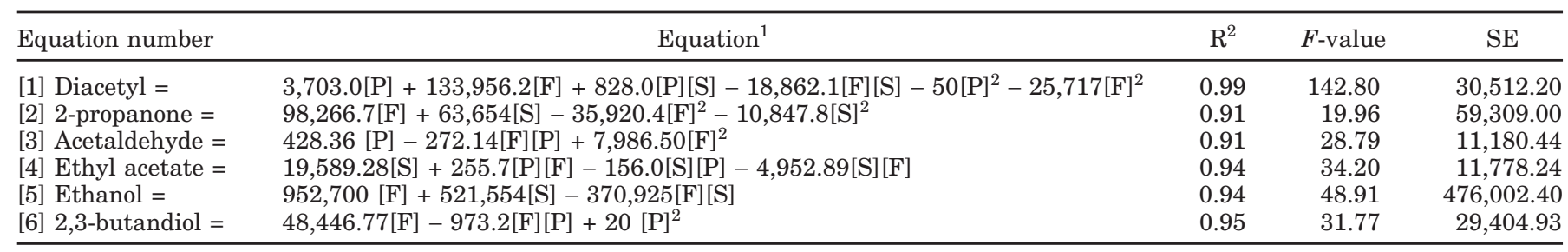

${ }^{1}[\mathrm{P}]=$ pressure level $(\mathrm{MPa}) ;[\mathrm{F}]=$ milkfat $\left.(\%) ; \mathrm{S}\right]=$ nonfat milk solids $(\%)$. Only terms with $P<0.05$ were included.

${ }^{2} \mathrm{R}=$ regression coefficient.

was significantly affected by HPH treatment. In fact, rheological parameters such as firmness, viscosity index, and consistency increased with pressure level for added nonfat milk solid concentrations $<3 \%$. When $\mathrm{S}$ was $>3 \%$, different yogurt rheological behaviors were observed. These behaviors can be explained with the modification induced by HPH treatment on casein-casein or casein-fat interactions (Kheadr et al., 2002; Lanciotti et al., 2004b). In addition, HPH of milk is reported to improve the coagulation characteristics of milk due to the modification of the balance between insoluble and soluble forms of calcium, phosphorus, and nitrogen (Lopez-Fandiño et al., 1998; Kheadr et al., 2002; Lanciotti et al., 2006). Moreover, Guerzoni et al. (1999) reported that HPH treatment induces increased exposure of the hydrophobic regions of proteins. Haque et al. (2001) attributed the improvement of textural properties of fermented milks to the progressive increase in the extent and strength of hydrophobic associations between proteins. Analogously, Subirade et al. (1998) showed that, although the HPH treatment did not affect the secondary structure of $\beta$ LG, this protein was stabilized by different electrostatic interactions before and after treatment. The modifications induced by HPH on the food matrix depends on several factors including treatment severity (i.e., pressure level, number of pressure cycles), inlet and outlet temperature of treated fluids, and the physicochemical and compositional characteristics of raw material (Lanciotti et al., 1996; Kheadr et al., 2002; Vachon et al., 2002). Consequently, as suggested by the data obtained in the present work, the HPH process has to be calibrated in relation to the composition of the basal medium and to the desired features of the final products. Acetaldehyde, ethanol, 2-propanone, diacetyl, and 2-butanone are regarded the main aroma compounds of yogurt-type products (Ott et al., 1997). In particular, acetaldehyde and diacetyl are considered the key metabolites for the quality of fermented milks. In cheese, cultured buttermilk, and butter, acetaldehyde is considered an undesirable compound, giving an atypical taste, whereas in yogurt and fermented milks, relatively large amounts are required to give the characteristic flavor of those products (Tamime and Robinson, 1999). The accumulation of acetaldehyde in growth medium depends on whether the microorganism has active enzymes that convert acetaldehyde to other metabolites, principally ethanol (Gonzalez et al., 1994). In addition, diacetyl is a very important compound that determines the specific characteristics of fermented milks (Oberman and Libudzisz, 1998). The production rates and amounts of diacetyl and acetoin in mesophilic starter cultures are dependent on the rate of citrate metabolism. The loss

Table 5. Best-fit equations relative to the effects of pressure level, milkfat, and nonfat milk solids concentrations on aroma compound accumulation, after $30 \mathrm{~d}$ of refrigerated storage, in coagula obtained with unhomogenized UHT cream by Lactobacillus paracasei BFE 5264 fermentation

\begin{tabular}{llcrr}
\hline Equation number & \multicolumn{1}{c}{ Equation $^{1}$} & $\mathrm{R}^{2}$ & $F$-value & \multicolumn{1}{c}{$\mathrm{SE}$} \\
\hline [1] Diacetyl $=$ & $2,228.3[\mathrm{P}]+33,801.75[\mathrm{~S}]-652.8[\mathrm{P}][\mathrm{S}]$ & 0.94 & 32.51 & $50,623.00$ \\
[2] 2-propanone $=$ & $92,021.8[\mathrm{~F}]+41,230.3[\mathrm{~S}]-2,605.1[\mathrm{~F}][\mathrm{S}]$ & 0.91 & 16.86 & $85,682.90$ \\
[3] Acetaldehyde $=$ & $0.63[\mathrm{P}]$ & 0.91 & 22.35 & $25,459.00$ \\
[4] Ethyl acetate $=$ & $475.3[\mathrm{P}]+20,110.66[\mathrm{~F}]-293.7[\mathrm{~F}][\mathrm{P}]$ & 0.95 & 49.67 & $11,234.70$ \\
{$[5]$ Ethanol $=$} & $708,197.5[\mathrm{~S}]-96,863.2[\mathrm{~S}]^{2}$ & 0.94 & 67.10 & $404,863.30$ \\
[6] 2,3-butandiol $=$ & $119,746.5[\mathrm{~F}]+411[\mathrm{~S}][\mathrm{P}]-47,732.0[\mathrm{~F}]^{2}-4,935.3[\mathrm{~S}]^{2}$ & 0.91 & 10.14 & $51,713.38$ \\
\hline
\end{tabular}

${ }^{1}[\mathrm{P}]=$ pressure level $(\mathrm{MPa}) ;[\mathrm{F}]=$ milkfat $(\%) ;[\mathrm{S}]=$ nonfat milk solids $(\%)$. Only terms with $P<0.05$ were included.

${ }^{2} \mathrm{R}=$ regression coefficient. 

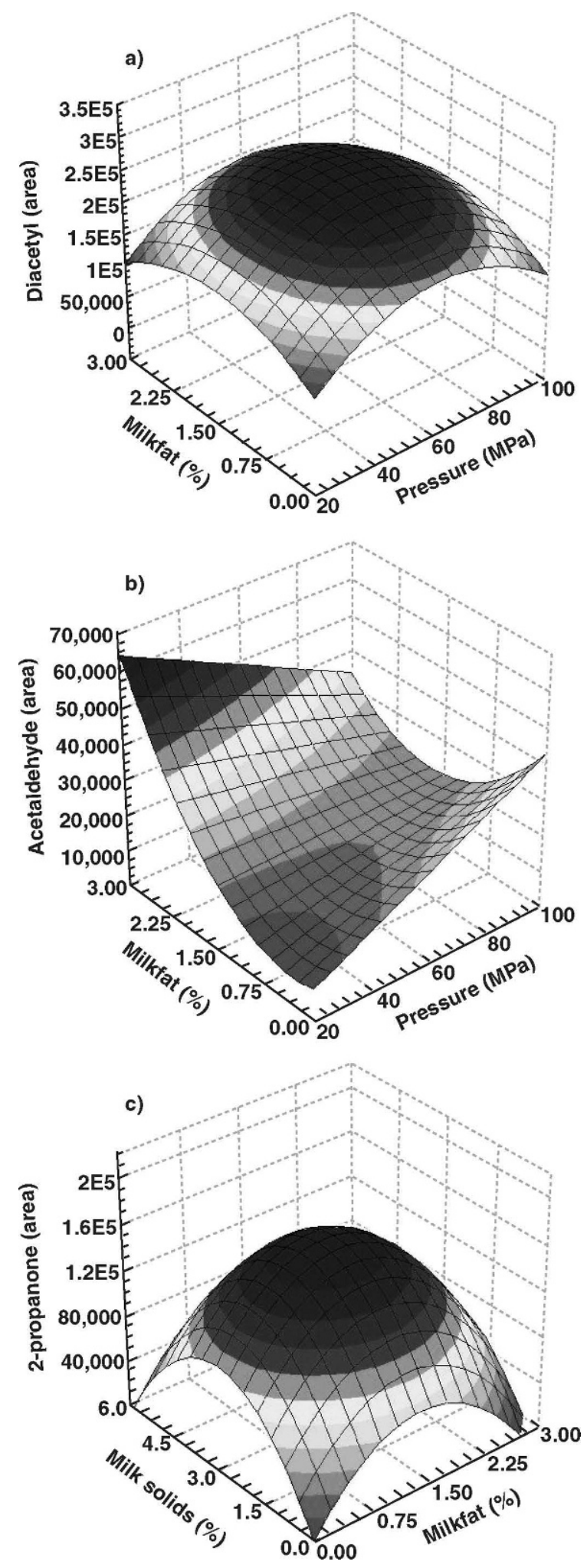

Figure 3. Three-dimensional contour plots showing the effect of the interaction $[\mathrm{P}] \times[\mathrm{F}]$ and $[\mathrm{F}] \times[\mathrm{S}]$ on (a) diacetyl, (b) acetaldehyde, and (c) 2-propanone accumulation in the final products after $12 \mathrm{~h}$ of refrigerated storage. $[\mathrm{P}]=$ homogenization pressure level $(\mathrm{MPa}) ;[\mathrm{F}]=$ milkfat $(\%) ;[\mathrm{S}]=$ nonfat milk solids $(\%)$.

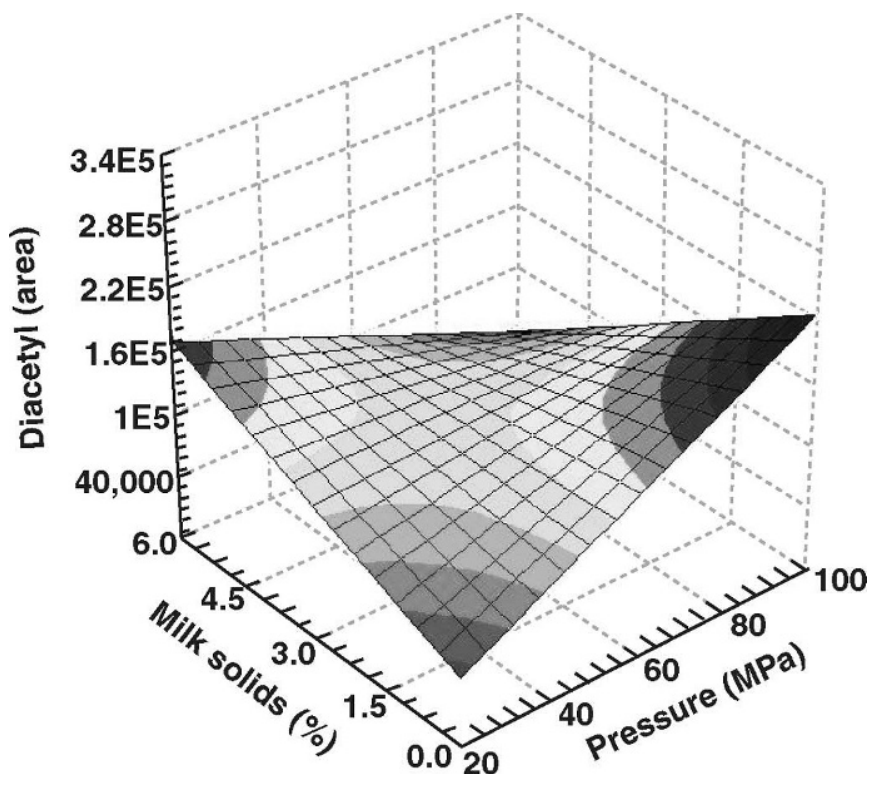

Figure 4. Three-dimensional contour plots showing the effect of the interaction $[\mathrm{S}] \times[\mathrm{P}]$ on diacetyl accumulation in final products after $30 \mathrm{~d}$ of refrigerated storage. $[\mathrm{P}]=$ homogenization pressure level $(\mathrm{MPa}) ; \mathrm{S}]=$ nonfat milk solids $(\%)$.

of flavor in fermented milk products due to the reduction of diacetyl is a problem and is affected by the redox potential of the milk and the requirement for the regeneration of NAD (Oberman and Libudzisz, 1998). Several approaches have been used to achieve high levels of diacetyl or acetaldehyde in fermented milks. The addition of citrate to the milk, either pre- or postfermentation, immediate cooling of the fermented milk before complete citrate utilization, temperature variation, aeration, and strain selection have been proposed to increase the level of diacetyl in fermented milk products (Rattray et al., 2000). The addition of whey protein and threonine to raw milk has been proposed to reduce the defects of fermented milks containing Lactobacillus acidophilus due the low concentration of acetaldehyde (Østlie et al., 2003). In fact, the acetaldehyde can derive from amino acid metabolism (Marshall and Cole, 1983). Also, the modulation of compositional variables, such as milkfat and nonfat milk solids, as well as incubation temperature and inoculum level have been reported as feasible strategies to improve the aromatic profiles of bioyogurt (Gardini et al., 1999; Østlie et al., 2005). The present work indicates that HPH could also be used for the production of fermented milks with increased content of characteristic molecules such as diacetyl and acetaldehyde or with specific aromatic profiles. These results could be due to the combination of events associated with homogenization. In fact, $\mathrm{HPH}$ is reported to increase the nitrogen 
Table 6. Sensory attribute mean score $\left( \pm\right.$ SD) for fermented milks in relation to the run conditions ${ }^{1}$

\begin{tabular}{lcccc}
\hline Run & Color & Firmness & Taste & Flavor \\
\hline 1 & $9.00 \pm 1.26^{\mathrm{a}}$ & $8.80 \pm 1.16^{\mathrm{a}}$ & $8.82 \pm 1.38^{\mathrm{a}}$ & $8.05 \pm 1.16^{\mathrm{a}}$ \\
2 & $7.02 \pm 1.78^{\mathrm{ab}}$ & $5.05 \pm 1.09^{\mathrm{b}}$ & $3.05 \pm 1.15^{\mathrm{cd}}$ & $3.20 \pm 1.26^{\mathrm{cd}}$ \\
3 & $4.22 \pm 1.79^{\mathrm{b}}$ & $8.10 \pm 1.39^{\mathrm{a}}$ & $5.00 \pm 1.04^{\mathrm{bc}}$ & $5.00 \pm 1.05^{\mathrm{bc}}$ \\
4 & $4.33 \pm 1.76^{\mathrm{b}}$ & $8.22 \pm 0.60^{\mathrm{a}}$ & $5.10 \pm 1.32^{\mathrm{bc}}$ & $4.82 \pm 1.20^{\mathrm{bc}}$ \\
5 & $7.10 \pm 1.41^{\mathrm{ab}}$ & $5.00 \pm 1.05^{\mathrm{b}}$ & $7.22 \pm 1.40^{\mathrm{ba}}$ & $3.19 \pm 0.89^{\mathrm{bc}}$ \\
6 & $7.10 \pm 0.63^{\mathrm{ab}}$ & $5.05 \pm 0.98^{\mathrm{b}}$ & $5.00 \pm 1.25^{\mathrm{bc}}$ & $7.06 \pm 0.63^{\mathrm{ab}}$ \\
7 & $7.00 \pm 1.41^{\mathrm{ab}}$ & $9.10 \pm 0.75^{\mathrm{a}}$ & $5.50 \pm 1.15^{\mathrm{bc}}$ & $5.00 \pm 1.18^{\mathrm{bc}}$ \\
8 & $8.20 \pm 1.28^{\mathrm{ab}}$ & $8.90 \pm 0.50^{\mathrm{a}}$ & $7.25 \pm 2.28^{\mathrm{ab}}$ & $8.14 \pm 0.80^{\mathrm{a}}$ \\
9 & $6.90 \pm 1.40^{\mathrm{ab}}$ & $7.05 \pm 1.62^{\mathrm{ab}}$ & $2.70 \pm 0.75^{\mathrm{d}}$ & $1.70 \pm 0.50^{\mathrm{d}}$ \\
10 & $7.05 \pm 1.41^{\mathrm{ab}}$ & $6.35 \pm 1.55^{\mathrm{ab}}$ & $3.00 \pm 0.63^{\mathrm{d}}$ & $2.00 \pm 0.49^{\mathrm{d}}$ \\
11 & $7.31 \pm 1.39^{\mathrm{ab}}$ & $6.03 \pm 0.94^{\mathrm{ab}}$ & $7.09 \pm 1.38^{\mathrm{ab}}$ & $5.00 \pm 0.95^{\mathrm{bc}}$ \\
12 & $6.85 \pm 1.50^{\mathrm{ab}}$ & $6.10 \pm 0.55^{\mathrm{ab}}$ & $6.97 \pm 1.10^{\mathrm{ab}}$ & $7.20 \pm 1.41^{\mathrm{ab}}$ \\
13 & $7.00 \pm 1.40^{\mathrm{ab}}$ & $6.02 \pm 1.42^{\mathrm{ab}}$ & $6.06 \pm 0.59^{\mathrm{b}}$ & $7.00 \pm 1.38^{\mathrm{ab}}$ \\
14 & $7.08 \pm 1.47^{\mathrm{ab}}$ & $5.95 \pm 1.23^{\mathrm{ab}}$ & $5.00 \pm 0.60^{\mathrm{bc}}$ & $6.91 \pm 1.02^{\mathrm{ab}}$ \\
15 & $7.04 \pm 1.38^{\mathrm{ab}}$ & $8.27 \pm 0.57^{\mathrm{a}}$ & $2.81 \pm 0.98^{\mathrm{d}}$ & $1.70 \pm 0.59^{\mathrm{d}}$ \\
16 & $7.20 \pm 1.40^{\mathrm{ab}}$ & $6.06 \pm 1.62^{\mathrm{ab}}$ & $2.82 \pm 1.00^{\mathrm{d}}$ & $8.05 \pm 0.90^{\mathrm{a}}$ \\
17 & $6.90 \pm 1.46^{\mathrm{ab}}$ & $7.19 \pm 1.33^{\mathrm{ab}}$ & $2.88 \pm 0.87^{\mathrm{d}}$ & $1.80 \pm 0.60^{\mathrm{d}}$ \\
\hline
\end{tabular}

${ }^{\mathrm{a}-\mathrm{d}}$ For each run considered, values with the same letter are not statistically different $(P>0.05)$ according to the post-hoc comparisons of the ANOVA.

${ }^{1}$ The results of the ANOVA are reported for each sensory attribute. The results are the mean of the panelist evaluations based on a scale where $0=$ very poor and $10=$ excellent.

fraction soluble at pH 4.6 (Rudan et al., 1998), the susceptibility to proteolysis of whey proteins and caseins, and consequently, the availability of free amino acids regarded as precursors of acetaldehyde (GarciaRisco et al., 2002). Moreover, Hayes and Kelly (2003) reported that the HPH treatment of skim milk induced a $\mathrm{pH}$ decrease more or less pronounced in relation to the severity of the treatment. This $\mathrm{pH}$ drop could positively affect the production of diacetyl. It is well known that the production of neutral molecules such as diacetyl is stimulated under unfavorable $\mathrm{pH}$ conditions in lactic acid bacteria (Hugenholtz, 1993). Moreover, the shift in metabolic pathway in response to environmental conditions is well documented in the case of homofermentative and heterofermentative lactobacilli (Axelsson, 1998). The conformational and physicochemical modifications of milk proteins resulting in microstructure changes are reported to have indirect effects on microbial growth and metabolism. In particular, Lanciotti et al. (2004b) demonstrated that the HPH treatment of milk enhanced the viability of Strep. thermophilus and Lb. delbrueckii ssp. bulgaricus during refrigerated storage of yogurt and favored the growth of Strep. thermophilus compared with that of Lb. delbrueckii ssp. bulgaricus; thus, reducing the risks of postacidification. Moreover, Guerzoni et al. (1997) observed that HPH could be used to modulate the size of water droplets in the emulsions or the cavities included in the lipid-protein matrices of model light dairy products. The extent of microbial growth was proportional to the aqueous cavity size. Verrips (1989) reported that in some dairy products, microbial growth could be confined to the aqueous microzones included in the physically stable lipid-protein matrix. These findings are in agreement with the data concerning the time of milkfat supplementation. In fact, the addition of UHT cream before the HPH milk treatment generated greater compartmentalization of the aqueous phase in the lipid-protein gel matrix with a consequent reduction of nutrient diffusion, microbial growth, and acidification rates.

\section{CONCLUSIONS}

The results obtained showed that HPH was able to differently affect the sensorial and microbiological features of fermented milks in relation to its application time and to the interaction with the compositional variables of the system. However, the use of a CCD allowed us to demonstrate the effects of the compositional variables on the rheological and microbiological features of fermented milks in relation to the severity of the treatment applied to the raw material. In particular, the polynomial models obtained and the relative response surfaces permitted us to identify the levels of the 3 independent variables able to maximize the growth of the probiotic strain during the fermentation process and to minimize the loss of viability of the strain during the refrigerated storage. However, further studies regarding the maintenance of the probiotic properties of $L b$. paracasei BFE 5264 in HPH fermented milk should be developed.

The application of $\mathrm{HPH}$, when optimized in relation to the process and final product, is a useful tool to differentiate the probiotic fermented milks, and thereby expand the range of products to satisfy the 
heterogeneous consumer demand. Otherwise, the probiotic fermented milk sector is characterized, compared with the traditional yogurt sector, by a wide offering of products that are homogeneous for sensorial features.

\section{REFERENCES}

Axelsson, L. 1998. Lactic acid bacteria: Classification and physiology. Pages 1-72 in Lactic Acid Bacteria; Microbiology and Functional Aspects. S. Salminen and A. Von Wright, ed. Marcel Dekker Inc., New York, NY.

Bertazzoni Minelli, E., A. Benini, M. Marzotto, A. Sbarbati, O. Uzzenente, R. Errario, H. Hendriks, and F. Dell'aglio. 2004. Assessment of novel probiotic Lactobacillus casei strains for the production of functional dairy foods. Int. Dairy J. 14:723-736.

Box, G. E. P., W. G. Hunter, and J. S. Hunter. 1978. An introduction to design data analysis and models building. Page 398 in Statistics for Experimenters. John Wiley \& Sons, New York, NY.

De Ancos, B., M. P. Cano, and R. Gomez. 2000. Characteristics of stirred low-fat yoghurt as affected by high pressure. Int. Dairy J. 10:105-111.

Floury, J., A. Desrumaux, and J. Lardières. 2000. Effect of high pressure homogenization on droplet size distribution and rheological properties of model oil-in-water emulsions. Innov. Food Sci. Emerg. Technol. 1:127-134.

Garcia-Risco, M. R., M. Ramos, and R. Lopez-Fandino. 2002. Modifications in milk proteins induced by heat treatment and homogenization and their influence on susceptibility to proteolysis. Int. Dairy J. 12:679-688.

Gardini, F., R. Lanciotti, M. E. Guerzoni, and S. Torrioni. 1999. Evaluation of aroma production and survival of Streptococcus thermophilus, Lactobacillus delbrueckii subsp. bulgaricus and Lactobacillus acidophilus in fermented milks. Int. Dairy J. 9:125-134.

Gomes, A. M. P., and F. X. Malcata. 1999. Bifidobacterium spp. and Lactobacillus acidophilus: Biological, biochemical, technological and therapeutical properties relevant for use as probiotics. Trends Food Sci. Technol. 10:139-157.

Gonzalez, S., V. Morata de Ambrosini, M. Manca de Nadra, A. de Ruiz Holgado, and G. Oliver. 1994. Acetaldehyde production by strains used as probiotics in fermented milk. J. Food Prot. $57: 436-490$.

Guerzoni, M. E., R. Lanciotti, F. Westall, and P. Pittia. 1997. Interrelationship between chemico-physical variables, microstrucutre and growth of Listeria monocytogenes and Yarrowia lipolytica in food model systems. Sci. Alimentari 17:497-512.

Guerzoni, M. E., L. Vannini, C. Chaves-López, R. Lanciotti, G. Suzzi, and A. Gianotti. 1999. Effect of high pressure homogenization on microbial and chemico-physical characteristics of goat cheeses. J. Dairy Sci. 82:851-862.

Guerzoni, M. E., L. Vannini, R. Lanciotti, and F. Gardini. 2002. Optimisation of the formulation and of the technological process of egg-based products for the prevention of Salmonella enteritidis survival and growth. Int. J. Food Microbiol. 73:367-374.

Haque, A., R. K. Richardson, and E. R. Morris. 2001. Effect of temperature on the rheology of set and stirred yogurt. Food Hydrocoll. 15:593-602.

Hayes, M. G., and A. L. Kelly. 2003. High pressure homogenisation of milk (b) effects on indigenous enzymatic activity. J. Dairy Res. 70:307-313.

Herrero, A. M., and T. Requena. 2006. The effect of supplementing goats milk with whey protein concentrate on textural properties of set-type yoghurt. Int. J. Food Sci. Technol. 41:87-92.

Holzapfel, W. H., P. Haberer, J. Snel, U. Schillinger, and J. H. J. Huis in't Veld. 1998. Overview of gut flora and probiotics. Int. J. Food Microbiol. 41:85-101.

Hugenholtz, J. 1993. Citrate metabolism in lactic acid bacteria. FEMS Microbiol. Rev. 12:165-178.
ISO. 1988. Sensory analysis. Standard 8589: General guidance for the design of test rooms. International Organization for Standardization, Geneva, Switzerland.

Iucci, L., F. Patrignani, M. Vallicelli, M. E. Guerzoni, and R. Lanciotti. 2006. Effects of high pressure homogenization on the activity of lysozyme and lactoferrin against Listeria monocytogenes. Food Contr. 18:558-565.

Kaláb, M., P. Allan-Wojtas, and B. E. Phipps-Todd. 1983. Development of microstructure in set-style nonfat yoghurt. A review. Food Microstruct. 2:51-66.

Kheadr, E. E., J. F. Vachon, P. Paquin, and I. Fliss. 2002. Effect of dynamic high pressure on microbiological, rheological and microstructural quality of Cheddar cheese. Int. Dairy J. 12:435-446

Kristo, E., C. G. Biliaderis, and N. Tzanetakis. 2003. Modelling of rheological, microbiological and acidification properties of a fermented milk product containing a probiotic strain of Lactobacillus paracasei. Int. Dairy J. 13:517-528.

Lanciotti, R., C. Chaves-Lopez, F. Patrignani, A. Papparella, M. E. Guerzoni, A. Serio, and G. Suzzi. 2004a. Effects of milk treatment with dynamic high pressure on microbial populations, and lipolytic and proteolytic profiles of Crescenza cheese. Int. J. Dairy Technol. 57:19-25.

Lanciotti, R., F. Gardini, M. Sinigaglia, and M. E. Guerzoni. 1996. Effects of growth conditions on the resistance of some pathogenic and spoilage species to high pressure homogenization. Lett. Appl. Microbiol. 22:165-168.

Lanciotti, R., L. Vannini, F. Patrignani, L. Iucci, M. Vallicelli, M. Ndagijimana, and M. E. Guerzoni. 2006. Effect of high pressure homogenisation of milk on cheese yield and microbiology, lipolysis and proteolysis during ripening of Caciotta cheese. J. Dairy Res. 73:1-11.

Lanciotti, R., L. Vannini, P. Pittia, and M. E. Guerzoni. 2004b. Suitability of high-dynamic-pressure-treated milk for the production of yoghurt. Food Microbiol. 21:753-760.

Lopez-Fandiño, R., M. G. De la Fuente, M. Ramos, and A. Olano. 1998. Distribution of minerals and proteins between the soluble and colloidal phases of pressurised milks from different species. J. Dairy Res. 65:69-78.

Lucey, J. A. 2004. Cultured dairy products: An overview of their gelation and texture properties. Int. J. Dairy Technol. 57:77-84.

Marshall, V. M., and W. M. Cole. 1983. Threonine aldolase and alcohol dehydrogenase activities in Lactobacillus bulgaricus and Lactobacillus acidophilus and their contribution to flavour production in fermented milks. J. Dairy Res. 50:375-379.

Mathara, J. M., U. Schillinger, P. Kutima Musive, S. K. Mbugua, and W. H. Holzapfel. 2004. Functional characteristics of lactic acid bacteria isolated from traditional Maasai fermented milk products in Kenya. Page 382 in Proc. 19th Int. ICFMH Symp., Food Micro 2004, Porto Roz, Slovenia. P. Raspov, Slovenia.

Mattila-Sandholm, T., P. Myllarinen, R. Crittenden, G. Mogensen, R. Fonden, and M. Saarela. 2002. Technological challenges for future probiotic foods. Int. Dairy J. 12:173-182.

Mitsuoka, T. 1992. The human gastrointestinal tract. Pages 69-113 in The Lactic Acid Bacteria in Health and Disease. B. J. B. Wood, ed. Elsevier, Amsterdam, the Netherlands.

Oberman, H., and Z. Libudzisz. 1998. Fermented milks. Pages 309350 in Microbiology of Fermented Foods. B. J. B. Wood, ed. Blackie Academic and Professional, London, UK.

Oliveira, M. N., I. Sodini, F. Remeuf, and G. Corrieu. 2001. Effect of milk supplementation and culture composition on acidification, textural properties and microbiological stability of fermented milks containing probiotic bacteria. Int. Dairy J. 11:935-942.

Østlie, H. M., M. H. Helland, and J. A. Narvhus. 2003. Growth and metabolism of selected strains of probiotic bacteria in milk. Int. J. Food Microbiol. 87:17-27.

Østlie, H. M., T. Treimo, and J. A. Narvhus. 2005. Effect of temperature on growth and metabolism of probiotic bacteria in milk. Int. Dairy J. 15:989-997.

Ott, A., L. B. Fay, and A. Chaintreau. 1997. Determination and origin of the aroma impact compounds of yogurt flavor. J. Agric. Food Chem. 45:850-858. 
Ouwehand, A., C. Kirjavainen, V. Pirkka, C. Shortt, and S. Salminen. 1999. Probiotics: Mechanisms and established effects. Int. Dairy J. 9:43-52.

Patrignani, F., R. Lanciotti, J. Maina Mathara, M. E. Guerzoni, and W. H. Holzapfel. 2006. Potential of functional strains, isolated from traditional Maasai milk, as starters for the production of fermented milks. Int. J. Food Microbiol. 107:1-11.

Rattray, F. P., M. Walfridsson, and D. Nilsson. 2000. Purification and characterization of a diacetyl reductase from Leuconostoc pseudomesenteroides. Int. Dairy J. 10:781-789.

Rudan, M. A., D. M. Barbano, M. R. Guo, and P. S. Kindstedt. 1998. Effect of the modification of fat particle size by homogenization on composition, proteolysis, functionality, and appearance of reduced fat mozzarella cheese. J. Dairy Sci. 81:2065-2076.

Saarela, M., G. Mogensen, R. Fondén, J. Matto, and T. MattilaSandholm. 2000. Probiotic bacteria: Safety, functional and technological properties. J. Biotechnol. 84:197-215.

Subirade, M., F. Loupil, A. F. Allain, and P. Paquin. 1998. Effect of dynamic high pressure on the secondary structure of $\beta$-lactoglobulin and on its conformational properties as determined by Fourier transform infrared spectroscopy. Int. Dairy J. 8:135140.
Tamime, A. Y., and R. K. Robinson. 1999. Biochemistry of fermentation. Pages 433-485 in Yoghurt: Science and Technology. A. Y. Tamime and R. K. Robinson, ed. Pergamon Press, Oxford, UK.

Thiebaud, M., E. Dumay, L. Picart, J. P. Guiraud, and J. C. Cheftel. 2003. High-pressure homogenization of raw bovine milk. Effects on fat globule size distribution and microbial inactivation. Int. Dairy J. 13:427-439.

Vachon, J. F., E. E. Kheadr, J. Giasson, P. Paquin, and I. Fliss. 2002. Inactivation of foodborne pathogens in milk using dynamic high pressure. J. Food Prot. 65:345-352.

Vannini, L., R. Lanciotti, D. Baldi, and M. E. Guerzoni. 2004. Interactions between high pressure homogenization and antimicrobial activity of lysozyme and lactoperoxidase. Int. J. Food Microbiol. 94:123-135.

Verrips, C. T. 1989. Growth of microorganisms in compartmentalized products. Pages 363-369 in Mechanisms of Action of Food Preservation Procedures. G. W. Gould, ed. Elsevier Applied Science, London, UK.

Vinderola, C. G., N. Bailo, and J. A. Reinheimer. 2000. Survival of probiotic microflora in Argentinian yogurts during refrigerated storage. Food Res. Intern. 33:97-102. 